Development and feasibility of the Help

to Overcome Problems Effectively

(HOPE) self-management intervention for people living with multiple sclerosis

Anderson, JK

http://hdl.handle.net/10026.1/16323

10.1080/09638288.2016.1181211

Disability and Rehabilitation

Informa UK Limited

All content in PEARL is protected by copyright law. Author manuscripts are made available in accordance with publisher policies. Please cite only the published version using the details provided on the item record or document. In the absence of an open licence (e.g. Creative Commons), permissions for further reuse of content should be sought from the publisher or author. 
See discussions, stats, and author profiles for this publication at: https://www.researchgate.net/publication/303886937

\section{Development and feasibility of the Help to Overcome Problems Effectively} (HOPE) self-management intervention for people living with multiple sclerosis

Article in Disability and Rehabilitation · June 2016

DOI: 10.1080/09638288.2016.1181211

CITATIONS

8

3 authors:

Joanna Kosmala-Anderson

University of Cambridge

51 PUBLICATIONS 438 CITATIONS

SEE PROFILE

Wendy Clyne

University of Plymouth

47 PUBLICATIONS 1,547 CITATIONS

SEE PROFILE
READS

45

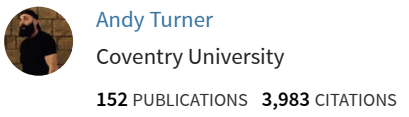

152 PUBLICATIONS 3,983 CITATIONS

SEE PROFILE

Some of the authors of this publication are also working on these related projects:

Project HOPE Programme (Help to Overcome Problems Effectively) View project

Building the evidence base for self management support interventions during the early detection of colorectal cancer for men. Protocol for a systematic review View project 
Disability and Rehabilitation

\title{
Development and feasibility of the Help to Overcome Problems Effectively (HOPE) self- management intervention for people living with multiple sclerosis
}

\author{
Joanna K. Anderson, Andy Turner \& Wendy Clyne
}

To cite this article: Joanna K. Anderson, Andy Turner \& Wendy Clyne (2016): Development and feasibility of the Help to Overcome Problems Effectively (HOPE) self-management intervention for people living with multiple sclerosis, Disability and Rehabilitation, DOI: 10.1080/09638288.2016.1181211

To link to this article: http://dx.doi.org/10.1080/09638288.2016.1181211

Published online: 09 Jun 2016.

Submit your article to this journal $₫$

LII Article views: 38

Q View related articles $\square$

View Crossmark data \lceil 


\title{
ORIGINAL ARTICLE
}

\section{Development and feasibility of the Help to Overcome Problems Effectively (HOPE) self-management intervention for people living with multiple sclerosis}

\author{
Joanna K. Anderson, Andy Turner and Wendy Clyne \\ Centre for Technology Enabled Health Research, Coventry University, Coventry, UK
}

\begin{abstract}
Purpose: To describe the development and feasibility of a self-management intervention called the Help to Overcome Problems Effectively (HOPE: MS), aimed at improving the physical and psychological wellbeing of people living with Multiple Sclerosis (MS).

Method: HOPE: MS is an innovative, 6-week group-based, manualised self-management intervention combining positive psychology theory and practice, and cognitive behavioural therapy (CBT). Participants $(N=21)$ recruited via a local East Midlands branch of the MS Society attended one of three HOPE: MS interventions and completed self-reported outcome measures in week 1 and week 6 . The following outcome measures were used: The Multiple Sclerosis Impact Scale; Multiple Sclerosis Fatigue Severity Scale; The Multiple Sclerosis Self-Efficacy Scale; The Adult State Hope Scale; The Hospital Anxiety and Depression Scale; The Positive and Negative Affect Scale.

Results: Post-intervention (6 weeks) mean scores decreased in the physical impact (baseline $M=65.6$, $\mathrm{SD}=17.4 ; 6$ weeks $\mathrm{M}=55.1, \mathrm{SD}=17.9,95 \% \mathrm{Cl}[-4.39,-16.47]$ and the psychological impact of MS (baseline $\mathrm{M}=24.0, \mathrm{SD}=7.3$; 6 weeks $\mathrm{M}=18.9 ; \mathrm{SD}=6.3,95 \% \mathrm{Cl}[-2.54,-7.66])$. There was also a decrease mean fatigue severity scores (baseline $49.4, S D=13.3,6$ weeks $M=41.1, S D=14.4,95 \% \mathrm{Cl}[-2.65$, -13.44]). There was a mean decrease in depression scores (baseline $M=6.9, S D=3.5 ; 6$ weeks $M=4.2$, $\mathrm{SD}=2.8,95 \% \mathrm{Cl}[-1.43,-4.00])$. There were smaller mean decreases in anxiety (baseline $\mathrm{M}=7.6, \mathrm{SD}=3.4$; 6 weeks $M=6.7(4.0), 95 \% \mathrm{Cl}[0.69,-2.50]$ ) and negative affect (baseline $M=22.9, S D=6.8 ; 6$ weeks $\mathrm{M}=20.8$ (8.1), 95\% Cl $[0.69,-2.50]$ ) refer Table 3). Mean MS self-efficacy scores (baseline 21.7, SD $=4.2 ; 6$ weeks $M=24.1, S D=4.7,95 \% \mathrm{Cl}[0.23,4.53]$ ), mean total hope scores (baseline $M=23.3, S D=10.7 ; 6$ weeks $M=32.2(10.6), 95 \% \mathrm{Cl}[4.91,12.9]$ ), hope agency scores (baseline $M=10.5, S D=5.7 ; 6$ weeks $M=15.7(6.2), 95 \% \mathrm{Cl}[2.37,8.01]$ ), hope pathways (baseline $M=12.9, S D=6.0 ; 6$ weeks $M=16.6$ (4.9), $95 \% \mathrm{Cl}[2.00,5.43]$ ) and positive affect scores increased (baseline $\mathrm{M}=27.3, \mathrm{SD}=7.1 ; 6$ months $\mathrm{M}=32.2$, $\mathrm{SD}=8.4,95 \% \mathrm{Cl}[0.42,9.39])$. Participants positively rated the intervention quality and delivery.

Conclusions: This feasibility study showed that the HOPE: MS was acceptable and useful to people living with MS. Further robust evaluations using a randomised controlled trial design with longer follow ups are needed to confirm early promising results of the HOPE: MS.
\end{abstract}

\section{- IMPLICATIONS FOR REHABILITATION}

- Living with MS requires constant adjustments to cope with unpredictable symptoms.

- Self-management interventions have the potential to help people living with MS to improve their quality of life.

- A feasibility study of the HOPE: MS self-management group-based intervention showed that it was acceptable and useful to people living with MS.

\section{ARTICLE HISTORY}

Received 12 March 2015

Revised 4 March 2016

Accepted 18 April 2016

Published online 30 May 2016

\section{KEYWORDS}

Hope; multiple sclerosis;

quality of life

self-management

\section{Introduction}

Multiple sclerosis (MS) is a chronic, progressive and currently incurable disease of the central nervous system, characterised by autoimmune inflammation, demyelination and axonal damage.[1] MS aetiology remains unknown, however an interaction between complex genetic factors and environmental influences seems to play a major role.[1] It is estimated that MS affects more than 2 million people worldwide [2] and approximately 127,000 adults in the UK, [3] and is the most common cause of neurological disability among young adults. MS symptom experience and symptom severity vary, depending upon the area of the brain in which lesions occur, thus no two cases of MS are exactly alike. Patients with relapsing-remitting MS after relatively symptom free periods experience flare-ups which duration and severity is highly unpredictable, while in secondary progressive MS the disease progresses continuously without remission.[1]

The most common MS symptoms include spasticity, weakness, tremor, balance and mobility problems, bladder and bowel dysfunctions, sexual dysfunctions, speech difficulties, swallowing difficulties and cognitive impairment.[4] The majority of people living with MS also experience severe fatigue [5] and depression.[6] It is estimated that up to $55 \%$ of people living with MS experience major depression in their lifetime.[7] Depression in MS has been

CONTACT Prof Andy Turner a.turner@coventry.ac.uk Centre for Technology Enabled Health Research, Coventry University, Priory Street, Coventry CV1 5FB, UK 
Table 1. HOPE: MS intervention content.

\begin{tabular}{ll}
\hline Session number & \multicolumn{1}{c}{ Session Activities } \\
\hline Session 1 & Welcome, introduction and ground rules \\
& What is self-management? \\
& Instilling hope: The upward spiral of positivity \\
& Diaphragmatic breathing \\
& Gratitude diary \\
& Goal setting and action planning \\
& Welcome and reflections from last week's session \\
& Solution focused goal feedback \\
Session 2 & Gratitude diary \\
& Managing stress \\
& Introduction to mindfulness \\
& Goal setting and action planning \\
& Welcome and reflections from last week's session \\
& Solution focused goal feedback \\
& Gratitude diary \\
& Managing fatigue \\
& Managing emotions \\
Session 3 & Guided imagery \\
& Goal setting and action planning \\
& Welcome and reflections from last week's session \\
& Solution focused goal feedback \\
& Gratitude diary \\
Sesy image, sexuality and intimacy & Communication \\
Session 4 & Goal setting and action planning \\
& Welcome and reflections from last week's session \\
& Solution focused goal feedback \\
& Gratitude diary \\
& Fear of relapse and disease progression \\
& Move and feel good \\
& Goal setting and action planning \\
& Welcome and reflections from last week's session \\
& Solution focused goal feedback \\
& Gratitude diary \\
& Character strengths \\
& Life priorities \\
& Motivational imagery \\
& Sharing successes \\
& Moving on and staying in touch \\
& \\
\hline & \\
Session & \\
&
\end{tabular}

associated with breakdowns in interpersonal relationships and employment, cognitive impairment, decreased adherence to treatment and greater suicide risk.[7]

Living with MS requires constant adjustments and the development of strategies to effectively cope with a wide array of unpredictable symptoms of the disease to maintain best possible health and quality of life.[8] The US Institute of Medicine describes self-management as "the tasks that individuals must undertake to live with one or more chronic conditions. These tasks include having the confidence to deal with medical management, role management and emotional management of their conditions".[9] Some of the main self-management skills include problem solving, decision making, resource utilisation, formation of a patient-provider partnership, action planning and goal-setting.[10]

As indicated in a report by the Consortium of Multiple Sclerosis Centres [11] participation in self-management support interventions is particularly important for people with MS. There is a large evidence base showing that MS self-management interventions underpinned by cognitive-behavioural approaches are effective in reducing depression,[7,12-15] stress,[5,16-19] perceived severity and impact of MS symptoms including fatigue and pain [20-22] and improving quality of life in people with MS.[23]

The aim of this feasibility study was to evaluate the acceptability and usefulness of a self-management intervention called the Help to Overcome Problems Effectively (HOPE: MS) intervention in improving the physical and psychological wellbeing of people living with MS.

\section{HOPE: MS intervention underpinning theory}

HOPE: MS is underpinned by positive psychology theory and research. We pursued this innovative approach to developing HOPE: MS because our evaluations of self-management interventions for other long term conditions identified a renewed sense of hope, a striving to use personal strengths in the pursuit of living well.[24-26] Positive psychology is concerned with the full range of human functioning and has the dual aims of alleviating psychological distress and promoting positive well-being. Professor Martin Seligman is attributed as responsible for officially launching positive psychology as a scientific endeavour during his American Psychological Association Presidential Lecture in 1998. However, as many others have noted, applied positive psychology has a research tradition which spans decades. Linley and Joseph [27] point out that cognitive behavioural therapy have a long tradition of using positive psychological techniques. Lopez et al. [28] have described the potential usefulness of positive psychology to complement CBT because of the shared focus on a strengths approach to adjustment and development of the two approaches. Karwoski et al. [29] suggest that there is considerable conceptual and technical overlap between CBT and positive psychological approaches including developing a strong therapeutic relationship between client and therapist/coach; focusing on goals; cognitive reappraisal/ mindfulness; scheduling pleasant activities; identifying and reviewing successes; monitoring mood; relaxation training and problem solving.

Snyder's hope theory [30] and Fredrickson's Broaden and Build theory [31] underpin HOPE: MS. Although hope theory is similar to self-efficacy theory, there are important differences.[32] Whereas self-efficacy theory focuses on specific goals and behaviours, hope theory recognises enduring cross-situational goals and behaviours, and is therefore highly relevant to the broader task of managing the diverse impact of living with a long term condition. Further, self-efficacy theory emphasises the role of agency beliefs, whereas hope theory proposes a cognitive set that includes both agency (goal directed determination) and pathways (planning of ways to meet goals).[32] Hope has been conceptualised and defined as "cognitive set that is based on a reciprocally-derived sense of successful agency (goal-directed determination) and pathways (planning to meet goals)".[32] As can be seen from Snyder's definition, goals are fundamental to hope theory. Pathway thoughts describe the perceived ability to produce plausible routes to goals, whereas agency thought is the motivational element, which focuses on commencing and persevering with goal pursuits. Pathway and agency thoughts are iterative and additive.[32]

A distinct feature of HOPE is a focus on an upward spiral of positive emotions [31] and experiences leading to greater wellbeing, resilience and coping. This contrasts with the more common approach used in other self-management interventions (e.g. the Expert Patient Programme [33]) that introduce a negative spiral of fear and frustration leading to negative health and wellbeing. Fredrickson (1998) suggests that increasing positive emotions and states is an efficient and often preferable approach to reducing negative emotions.[31] Fredrickson's broaden and build theory (1998) [31] suggests that positive emotions broaden an individual's attention, thinking and action thus enabling the building of new, creative thought and action pathways (i.e. expanding an individual's coping skills) and the building of personal and social resources.

There is a growing body of evidence that suggests that gratitude improves psychological well-being and increases positive emotions.[34,35] There have been a number of studies that have shown that interventions that increase gratitude are a promising 
clinical intervention for improving psychological well-being, but perhaps most significantly, depression.[36] There have been calls for further research into gratitude interventions as they could be more widely used in clinical settings.[38] A gratitude activity is a weekly feature in the HOPE: MS intervention. It is designed to increase participants' positive emotions. HOPE: MS also includes other evidence-based CBT and positive psychological activities such as identifying personal strengths, scheduling pleasant activities, mindfulness, relaxation training and reviewing successes.[29] Refer Table 1 for HOPE: MS weekly content.

HOPE: MS utilises Irvin Yalom's (2005) group curative factors, including instillation of hope, universality (realising you are not alone) and altruism.[37] Participants observe each other and the facilitators successfully overcoming the challenges of living with MS through achieving their weekly goals (instillation of hope), share common experiences (universality) and are encouraged to support each other through the provision of informational and emotional support (altruism).

\section{Development of the HOPE: MS intervention}

The HOPE: MS was developed with funding from the MS Society through their Small Grants Innovation Award Scheme. The MS Society is a UK charity providing information and support for people living with MS. Development and feasibility testing of HOPE: MS was guided by the MRC framework for developing and testing complex intervention [38] and involved consultations with MS health professionals and people living with MS. HOPE: MS is a group-based self-management intervention delivered in six weekly sessions each of $2.5 \mathrm{~h}$ duration. Two HOPE: MS interventions were delivered to 14 participants in total and feedback was obtained from five participants and three facilitators via focus groups and interviews about how to improve the process and content of the intervention. HOPE: MS was found to be acceptable in terms of format, content and delivery. Participants and facilitators mentioned that the most valued aspects of the intervention were goal setting and action planning, deep breathing exercises and sharing and learning with similar others. For some participants, the HOPE: MS intervention allowed them to be more positive about living with MS, particularly in terms of encouraging them to think about their strengths. Participants valued having the opportunity to share and learn with similar others. Participants felt supported and understood by the facilitators who had experienced and overcame similar challenges. Several changes were made to the intervention on the basis of this formative evaluation, including a more comprehensive and MS specific physical activity and fatigue management component, and the addition of an "open space forum" session in week 6 . The focus of the "open space forum" would be selected by the group and could address any specific concerns the group had which had not been covered in the intervention curriculum. Invited speakers could also contribute to this session. Other changes made to the intervention included using more interactive learning materials and activities such as information and educational videos (e.g. "The Science of Character"; https:// www.youtube.com/watch?v=U3nT2KDAGOc) quizzes, fatigue and pacing diaries, physical activity case studies and communication skills role playing) in the intervention delivery.

\section{HOPE: MS content and delivery}

Two people living with MS who had previous experience of delivering self-management interventions for the MS Society in the UK were recruited to deliver the HOPE: MS. Each session follows a similar pattern. There is a combination of psycho-education, skills practice, in-depth group discussion and setting and reviewing goals Participants set personally relevant and meaningful weekly goals, as "homework" tasks which they were invited to share with other group members and provide goal attainment or goal barrier feedback the following week. Goal setting and action planning are key behaviour change techniques that have a strong evidence base.[39,40] Other "homework" tasks include completing a fatigue and pacing diary and taking an online character strengths test.

\section{HOPE: MS facilitator training}

Facilitator training encompasses a 2-day classroom-based training course. The classroom training involves training in motivational interviewing (e.g. reflective listening) and behaviour change skills (e.g. goal setting, action planning), group facilitation skills (e.g. managing challenging behaviours) and delivery practice of intervention activities. Delivery is guided by a tutor's manual to ensure consistency of delivery and content. Facilitators were trained and accredited against a rigorous set of quality standards with training and intervention delivery focusing on adherence to the timing, sequence and coverage of activities as set out in the manual to ensure fidelity. Facilitators were observed delivering a session from the first HOPE: MS intervention and assessed using a fidelity checklist. Ongoing support was provided by one of the authors (AT) and the lead HOPE facilitator trainer, both of whom are experienced self-management trainers, having trained over 500 peer and professional facilitators.

\section{Feasibility study}

Participants were recruited via a local East Midlands branch of the MS Society at drop in sessions and the branch's annual conference. People living with MS were informed that the intervention would provide the opportunity to learn how to better manage their MS and to meet other people living with MS in a supportive group setting. In total, 25 people living with MS expressed an interest in attending the intervention and provided contact details. Four participants subsequently decided not to participate, because the timing of the intervention was inconvenient due to either holiday $(N=1)$ or work commitments $(N=1)$ or feeling unwell $(N=2)$.

The following inclusion/exclusion criteria were established:

Inclusion criteria:

- Diagnosis of any type of MS confirmed by neurologist.

- Aged 18 years and over.

- Ability to complete a questionnaire.

Exclusion criteria:

- Inability to understand and participate in an intervention delivered in English.

- Current participation in any other research study.

\section{Procedure}

Three HOPE interventions were delivered sequentially over a 12-month period. No changes were made to the intervention during this period. Participants completed outcome measures during session one (baseline) and session six (post-intervention). A selfmanagement intervention quality and delivery rating scale was completed during the last session of the intervention.

\section{Outcome measures}

Demographic information such as age, gender, ethnicity, type of MS and co-morbidity, was collected at baseline only (refer Table 2 for demographic variables). We used a range of outcome measures 
Table 2. Demographic characteristics of participants.

\begin{tabular}{lcc}
\hline Characteristics & $N$ & Mean (SD) \\
\hline Age: Mean (SD = standard deviation, range) & 21 & $54.3 \begin{array}{c}(10.5)(36-76) \\
\%\end{array}$ \\
Gender & \multicolumn{2}{c}{19} \\
$\quad$ Male & 4 & 81 \\
$\quad$ Female & 17 & \\
Ethnic origin & & 100 \\
$\quad$ White & 21 & \\
Type of MS & & 57.1 \\
$\quad$ Relapsing-remitting & 12 & 38.1 \\
$\quad$ Secondary progressive & 8 & 4.8 \\
$\quad$ Benign & 1 & 43 \\
Co-morbidity & 9 & \\
\hline
\end{tabular}

selected to best capture self-management outcomes relevant for people living with MS.

The Multiple Sclerosis Impact Scale (MSIS-29) [41] has 29 items; 21 relating to the physical impact of the condition (e.g. difficulties moving about indoors) and eight relating to psychological impact (e.g. feeling anxious or tense). The timeframe for completion is "in the previous two weeks" and each item is rated on a scale anchored at 1 (not at all) and 5 (extremely). Scores for physical and psychological impact are summed separately with higher scores indicating greater physical and psychological limitations.

The Multiple Sclerosis Fatigue Severity Scale [42] contains nine items relating to fatigue within the previous week with each item rated on a scale anchored at 1 (strongly disagree) and 7 (strongly agree) with higher scores indicating higher levels of fatigue. Example items include: Fatigue interferes with my physical functioning; Fatigue causes frequent problems for me.

The Multiple Sclerosis Self-Efficacy Scale [43] was used to determine the level of self-efficacy (confidence) each participant had in the previous week. Each of the 11 items is rated 1 (strongly agree) to 4 (strongly disagree); higher scores reflect greater self-efficacy. Example items include: Despite my difficulties, I still manage to cope with daily life; I am confident I can overcome my difficulties.

The Hospital Anxiety and Depression Scale (HADS) [30] comprises 14 items; seven assessing anxiety (e.g. Worrying thoughts go through my mind) and seven assessing depression (e.g. I look forward with enjoyment to things). Each item is rated 0-3; anxiety and depression scores are summed separately. Scores range from 0-21; higher scores indicate higher anxiety and depression.

The Positive and Negative Affect Scale (PANAS) [44] assesses positive and negative effect. The scale comprises 20 words, 10 describing positive affect (e.g. interested, excited) and 10 describing negative affect (e.g. upset, guilty). Each word is rated 1(very slightly or not at all) to 5 (extremely) indicating to what extent the participant had felt each emotion in the previous week. Scores for positive affect and negative affect are summed separately; higher scores indicate higher levels of positive and negative effect.

The Adult State Hope Scale [45] measures hope defined as the perceived "capability to derive pathways to desired goals, and motivate oneself via agency thinking to use those pathways".[34] The scale comprises six statements which represent pathways (e.g. There are lots of ways around any problem that I am facing now) and agency (e.g. At the present time, I am energetically pursuing my goals) beliefs. Participants indicate the extent to which they agree with each of the six statements on scale anchored at 1 (definitely false) and 8 (definitely true). Overall scores range from 6 to 48 with higher scores indicting higher levels of hopeful thinking. Scores for the Agency and Pathways subscale items are summed separately to provide scores between 3 and 24, with higher scores indicating more agency and pathways beliefs.
Intervention quality and delivery rating scale

The Health Education Impact Questionnaire (heiq) is a nine items scale [46] which assesses self-management intervention quality, and has been used to evaluate self-management interventions in the UK [47] and Australia.[46] Participants completed the heiq scale during the last session of the intervention. Responses to each of the nine items are scored: $1=$ Strongly Disagree, $2=$ Disagree, $3=$ Agee, $4=$ Strongly Agree. Higher scores indicate more positive feedback. Scores are averaged to provide a mean score for each item between 1 and 4. Example items include: "I intend to tell other people that the intervention is very worthwhile".; "The content was very relevant to my situation".

The study was approved by Coventry University Ethics Committee.

\section{Data analysis}

All data analyses were conducted using IBM SPSS Statistics version 20 (IBM Corporation, Armonk, NY). Descriptive statistics, mean (SD) and $95 \% \mathrm{Cl}$ are presented for baseline and post-intervention outcomes in keeping with studies with small sample sizes, which are not adequately powered for hypothesis testing.[48]

\section{Results}

All 21 participants completed the intervention (17 participants attended all 6 sessions; 2 attended 5 sessions and 2 attended 4 sessions) and completed baseline and post-intervention outcome measures.

\section{Demographic variables}

All the respondents were of White ethnic origin and a majority were women $(81 \%, n=17)$. Participants mean age was 54.3 years (SD 10.5 years; age range 36-76 years). Twelve respondents had relapsing-remitting $M S$, eight secondary progressive $M S$ and one participant had benign MS. Just under half of respondents $(43 \%$, $n=9$ ) had a co-morbid health condition in addition to MS. Participants' characteristics are summarised in Table 2.

\section{Outcomes}

Participation in HOPE: MS was associated with improvements in all MS-specific outcome measures. Table 3 shows that at the end of the 6-week intervention mean scores decreased in both the physical impact (baseline $M=65.6, S D=17.4 ; 6$ weeks $M=55.1$, $\mathrm{SD}=17.9,95 \% \mathrm{Cl}[-4.39,-16.47])$ and the psychological impact of $M S$ (baseline $M=24.0, S D=7.3 ; 6$ weeks $M=18.9 ; S D=6.3$, $95 \% \mathrm{Cl}[-2.54,-7.66])$, as measured by MSIS-29. There was also a decrease in mean fatigue severity scores (baseline 49.4, SD $=13.3$, 6 weeks $\mathrm{M}=41.1, \mathrm{SD}=14.4,95 \% \mathrm{Cl}[-2.65,-13.44])$ and mean MS self-efficacy scores increased (baseline 21.7, $S D=4.2 ; 6$ weeks $\mathrm{M}=24.1, \mathrm{SD}=4.7,95 \% \mathrm{Cl}[0.23,4.53])$

Participation in HOPE:MS was also associated with a mean decrease in depression scores (baseline $M=6.9, S D=3.5 ; 6$ weeks $\mathrm{M}=4.2, \mathrm{SD}=2.8,95 \% \mathrm{Cl}[-1.43,-4.00])$, increase in mean total hope scores (baseline $M=23.3, S D=10.7 ; 6$ weeks $M=32.2$ (10.6), $95 \% \mathrm{Cl}[4.91,12.9]$ ), hope agency scores (baseline $M=10.5$, $\mathrm{SD}=5.7 ; 6$ weeks $\mathrm{M}=15.7(6.2), 95 \% \mathrm{Cl}[2.37,8.01)]$, hope pathways (baseline $M=12.9, S D=6.0 ; 6$ weeks $M=16.6$ (4.9), $95 \% \mathrm{Cl}$ $[2.00,5.43]$ and positive affect (baseline $M=27.3, S D=7.1 ; 6$ months $\mathrm{M}=32.2, \mathrm{SD}=8.4,95 \% \mathrm{Cl}[0.42,9.39])$. There were smaller mean decreases in anxiety (baseline $M=7.6, S D=3.4 ; 6$ weeks $\mathrm{M}=6.7$ (4.0), $95 \% \mathrm{Cl}[0.69,-2.50]$ ) and negative affect (baseline 
Table 3. Changes in outcome measure scores (mean, (SD) $[95 \% \mathrm{CI}]$ ) pre- and 6 weeks post-HOPE: MS intervention.

\begin{tabular}{|c|c|c|c|}
\hline Measure & Mean (SD) baseline & Mean (SD) 6 weeks & $95 \% \mathrm{Cl}$ \\
\hline MSIS: Physical (21-105, $\downarrow=$ better) & $65.6(17.4)$ & $55.1(17.9)$ & {$[-4.39,-16.47]$} \\
\hline MSIS: Psychological (8-40, $\downarrow=$ better) & $24.0(7.3)$ & $18.9(6.3)$ & {$[-2.54,-7.66]$} \\
\hline MS: Fatigue Severity (9-63, $\downarrow=$ better) & $49.4(13.3)$ & $41.4(14.4)$ & {$[-2.65,-13.44]$} \\
\hline HADS: Anxiety ( $0-21, \downarrow=$ better) & $7.6(3.4)$ & $6.7(4.0)$ & {$[0.69,-2.50]$} \\
\hline HADS: Depression (0-21, $\downarrow=$ better) & $6.9(3.5)$ & $4.2(2.8)$ & {$[-1.43,-4.00]$} \\
\hline PANAS: Positive effect (10-50, $\uparrow=$ better) & $27.3(7.1)$ & $32.2(8.4)$ & {$[0.42,9.39]$} \\
\hline HOPE subscale: agency & $10.5(5.7)$ & $15.7(6.2)$ & {$[2.37,8.01]$} \\
\hline HOPE subscale: pathways & $12.9(6.0)$ & $16.6(4.9)$ & {$[2.00,5.43]$} \\
\hline
\end{tabular}

Table 4. Participants' rating of intervention quality and deliver rating (mean, SD).

\begin{tabular}{lr}
\hline Self-management intervention quality report items & Mean (SD) \\
\hline I intend to tell other people that the intervention is very worthwhile & $3.7(4.6)$ \\
The intervention has helped me set goals that are reasonable \& within reach & $3.6(0.5)$ \\
I trust the information and advice obtained from programme & $3.7(0.5)$ \\
Intervention tutors very well organised & $3.6(0.6)$ \\
I feel it was worth my time and effort to take part & $3.8(0.4)$ \\
Difficult topics and discussions were handled well by tutors & $3.8(0.4)$ \\
Content was very relevant to my situation & $3.7(0.6)$ \\
I feel that everyone in the intervention had the chance to speak if they wanted & $3.9(0.3)$ \\
The people in the group worked very well together & $4.0(0.0)$ \\
\hline
\end{tabular}

$\mathrm{M}=22.9, \mathrm{SD}=6.8 ; 6$ weeks $\mathrm{M}=20.8(8.1), 95 \% \mathrm{Cl}[0.69,-2.50]$; Table 3).

\section{Course quality and delivery}

Table 4 shows that the mean ratings for all nine items was 3.6 or above, indicating that participants rated the HOPE intervention delivery and quality positively.

\section{Discussion}

To the best of our knowledge, this is the first study to look at whether a self-management intervention developed combining positive psychology and CBT theory and practice is acceptable, and if it has the potential to be useful for people living with MS. All the 21 participants completed pre and post-intervention outcome measures and attended at least four sessions, which indicates the intervention is acceptable for people living with MS. The outcome measures reflected important aspects of living with MS including fatigue, anxiety, depression and physical limitations. In keeping with the positive psychological theory underpinning the intervention, we also used outcome measures which assessed positive affect and hope. Mean scores on all of the outcome measures improved and these improvements are in line with other feasibility trials we have conducted with HOPE interventions for cancer survivors [49] people living with HIV [50] and parent caregivers $[N=54]$ [51] The scale of the improvements are also consistent with randomised controlled trials of self-management interventions for people living with a range of long-term conditions, of a similar duration ( 6 weeks) delivered by peer facilitators.[33,44,52]

Positive psychology interventions should address illnesses that affect longevity, cause disability, have variable prognosis and can involve relapse.[53] Recently, self-management researchers have emphasised the importance of fostering hope and other positive psychological and emotional states in supporting people to manage their condition. [54,55]

Interventions such as HOPE: MS that have the potential to reduce depression associated with MS can potentially prevent the development of severe mood disorders, help reduce demand placed on psychological services and reduce healthcare costs. Several hope therapy based studies [56,57] involving older depressed adults in the US reported a statistically significant increase and large effect size improvement in hope and reduced feelings of hopelessness, anxiety and depression.

Chronic fatigue is considered by people affected by MS to be the most debilitating symptom and leads to most disruption in their everyday activities.[58] Improved self-management of fatigue can enable people living with MS to lead a more active life and as a result significantly improve patients' quality of life. MS self-efficacy, positive affect and hope scores all improved. Studies show that MS self-efficacy is an important predicator of self-reported physical, social and cognitive functioning in MS and plays a significant role in individual psychological adjustments to MS.[59] The improvements in positive affect and hope are important as they reflect the positive psychological theoretical underpinnings of HOPE: MS. High positive affect refers to a general tendency to experience a "state of high energy, full concentration and pleasurable engagement".[45] We have described elsewhere the important role positive emotions have among participants attending selfmanagement interventions in helping them to cope.[60] Moreover, focusing on positives is one of the predicators of better psychological adjustment to MS, higher levels of energy and reduced fatigue.[13] MS is often associated with loss of hope that can lead to depression.[12] Hope (goal directed agency and planning) has been shown to be a unique predictor of general wellbeing.[61]

Mean changes in anxiety and negative affect were smaller than the other outcomes. In an evaluation of an arthritis self-management intervention, we reported improvements in positive affect but not negative effect, at 12 months, similar to the results of this study.[62] Women with MS are particularly prone to anxiety disorders,[63] and since our sample included mostly females, we may speculate that they were more likely to experience some form of anxiety. Many studies have assessed the effectiveness of different kinds of interventions in reducing depression in people living with $M S$,[7] however studies examining the effectiveness of interventions in reducing anxiety are scarce thus it is difficult to speculate why mean improvements in anxiety scores were not similar to other outcome measures. Further studies are needed to determine 
what self-management interventions components are associated with lower anxiety.

The results of the heiq intervention quality and delivery report are positive and suggest that overall participants are satisfied with the quality of the programme, the delivery style and skills of the tutors. These results are similar to those reported by a large scale UK evaluation of a similar type of peer led self-management intervention.[46]

\section{Limitations}

The mean differences between pre and post-course scores were generally high, which is promising, but need to be interpreted with caution for several reasons. The study had a small sample size, and was uncontrolled. Only baseline and post intervention data were collected so we are unable to say whether the improvements are maintained in the longer term. The sample was selfselected, highly motivated and homogenous, with all participants being of White ethnic origin and the majority were women. It is possible that this self-selected group have a natural inclination to respond favourably to a positive psychological approach to managing their MS.

Post-intervention outcomes were collected during the last session in the presence of the facilitators, which introduces the risk of bias as participants may experience the Hawthorne effect [64] and give overly positive outcome scores. Further, the response time for some of the outcome measures meant that participants based their responses on a period before the intervention ended (e.g. PANAS, previous week, MSIS-29, previous 2 weeks). Finally, we did not collect any information about disease duration or level of disability.

An adequately powered, randomised controlled trial is needed to establish whether HOPE: MS has the potential to provide longer term positive effects and whether it is acceptable and useful in the long-term (6-12 months follow up). The sample should include participants of different ethnic origins, different types of MS, including those with primary progressive MS and men.

\section{Conclusion}

HOPE: MS is an innovative self-management intervention combining positive psychology theory and practice, and CBT. The intervention was acceptable and useful for people living with MS, and the quality of delivery was positively rated. Further robust evidence is needed of the impact of the HOPE: MS self-management intervention.

\section{Acknowledgement}

The development of the HOPE: MS Programme was funded by a MS Society Innovative Award.

\section{Disclosure statement}

The authors report no conflicts of interest.

\section{References}

[1] Comabella M, Khoury SJ. Immunopathogenesis of multiple sclerosis. Clin Immunol. 2012;142:2-8.

[2] World Health Organization. Atlas multiple sclerosis resources in the world 2008. Geneva: WHO Press; 2008.

[3] Mackenzie IS, Morant SV, Bloomfield GA, et al. Incidence and prevalence of multiple sclerosis in the UK 1990-2010: a descriptive study in the General Practice Research Database. J Neurol Neurosurg Psychiatry. 2014;85:76-84.

[4] Schapiro RT. Managing the symptoms of multiple sclerosis. 5th ed. New York: Demos Medical Publishing; 2012.

[5] Thomas SPW, Thomas P, Kersten R, et al. 134 Group-based cognitive behavioural approach to managing fatigue in multiple sclerosis is effective: a multi-centre parallel arm randomised controlled trial. J Neurol Neurosurg Psychiatry. 2012;83:e1.

[6] Jones $\mathrm{KH}$, Ford DV, Jones PA, et al. A large-scale study of anxiety and depression in people with multiple sclerosis: a survey via the web portal of the UK MS register. PLoS One. 2012;7:e41910.

[7] Hind D, Cotter J, Thake A, et al. Cognitive behavioural therapy for the treatment of depression in people with multiple sclerosis: a systematic review and meta-analysis. BMC Psychiatry. 2014;14:5.

[8] Plow MA, Finlayson M, Rezac M. A scoping review of selfmanagement interventions for adults with multiple sclerosis. PMR. 2011;3:251-262.

[9] US institute of medicine reference. Adams K, Greiner AC Corrigan JM, editors. The 1st Annual Crossing the Quality Chasm Summit - a focus on communities. Washington, DC: The National Academic Press; 2004. p. 57.

[10] Lorig KR, Holman HR. Self-management education: history, definition, outcomes, and mechanisms. Ann Behav Med. 2003;26:1-7.

[11] Fraser R, Johnson E, Edhe D, et al. Patient self-management in multiple sclerosis, White Paper. Hackensack, NJ: Consortium of Multiple Sclerosis Centers; 2009.

[12] Barnwell AM, Kavanagh DJ. Prediction of psychological adjustment to multiple sclerosis. Soc Sci Med. 1997;45:411-418.

[13] McCabe MP, McKern S, McDonald E. Coping and psychological adjustment among people with multiple sclerosis. J Psychosom Res. 2004;56:355-361.

[14] Rae-Grant AD, Turner AP, Sloan A, et al. Self-management in neurological disorders: systematic review of the literature and potential interventions in multiple sclerosis care. J Rehabil Res Dev. 2011;48:1087-1100.

[15] Thomas PW, Thomas S, Hillier C, et al. Psychological interventions for multiple sclerosis. Cochrane Database Syst Rev. 2006;1:CD004431.

[16] Mohr DC, Lovera J, Brown T, et al. A randomized trial of stress management for the prevention of new brain lesions in MS. Neurology. 2012;79:412-419.

[17] Tesar N, Baumhackl U, Kopp M, et al. Effects of psychological group therapy in patients with multiple sclerosis. Acta Neurol Scand. 2003;107:394-399.

[18] Foley FW, Bedell JR, LaRocca NG, et al. Efficacy of stressinoculation training in coping with multiple sclerosis. J Consult Clin Psychol 1987;55:919-922.

[19] Crawford JD, Mclvor GP. Stress management for multiple sclerosis patients. Psychol Rep. 1987;61:423-429.

[20] Knoop H, van Kessel K, Moss = Morris R. Which cognitions and behaviours mediate the positive effect of cognitive behavioural therapy on fatigue in patients with multiple sclerosis? Psychol Med. 2012;42:205.

[21] Moss-Morris R, McCrone P, Yardley L, et al. A pilot randomised controlled trial of an Internet-based cognitive behavioural therapy self-management intervention (MS Invigor8) for multiple sclerosis fatigue. Behav Res Ther. 2012;50:415-421. 
[22] Thomas PW, Thomas S, Kersten P, et al. Multi-centre parallel arm randomised controlled trial to assess the effectiveness and cost-effectiveness of a group-based cognitive behavioural approach to managing fatigue in people with multiple sclerosis. BMC Neurol. 2010;10:43.

[23] Cosio D, Jin L, Siddique J, et al. The effect of telephoneadministered cognitive-behavioral therapy on quality of life among patients with multiple sclerosis. Ann Behav Med. 2011;41:227-234.

[24] Turner A, Williams B, Barlow J. The impact of an arthritis self-management programme on psychosocial wellbeing. Health Educ. 2002;102:95-105.

[25] Barlow JH, Bancroft GV, Turner AP. Self-management training for people with chronic disease: a shared learning experience. J Health Psychol. 2005;10:863-872.

[26] Barlow J, Edwards R, Turner A. The experience of attending a lay-led, chronic disease self-management programme from the perspective of participants with multiple sclerosis. Psychol Health. 2009;24:1167-1180.

[27] Linley PA, Joseph S, editors. Positive psychology in practice. New York: John Wiley \& Sons; 2004.

[28] Lopez SJ, Edwards LM, Magyar-Mor JL, et al. Fulfilling its promise: counseling psychology's efforts to understand and promote optimal human functioning. In: Walsh WB, editor. Counseling psychology and optimal human functioning. Mahwah, NJ: Erlbaum; 2003. p. 297-307.

[29] Karwoski L, Garratt GM, llardi SS. On the integration of cognitive-behavioral therapy for depression and positive psychology. J Cogn Psychother. 2006;20:159-170.

[30] Snyder CR, Harris C, Anderson JR, et al. The will and the ways: development and validation of an individual-differences measure of hope. J Person Soc Psychol. 1991;60:570.

[31] Fredrickson BL. The role of positive emotions in positive psychology: the broaden-and-build theory of positive emotions. Am Psychol. 2001;56:218.

[32] Snyder CR. Hypothesis: there is hope. In: Snyder CR, editor. Handbook of hope: theory, measures and application. New York: Academic Press; 2000. p. 3-18.

[33] Kennedy $A$, Reeves $D$, Bower $P$, et al. The effectiveness and cost effectiveness of a national lay led self care support programme for patients with long-term conditions: a pragmatic randomised controlled trial. J Epidemiol Community Health. 2006;61:254-261.

[34] McCullough ME, Tsang JA, Emmons RA. Gratitude in intermediate affective terrain: links of grateful moods to individual differences and daily emotional experience. J Person Soc Psychol. 2004;86:295-309.

[35] Wood AM, Maltby J, Gillett R, et al. The role of gratitude in the development of social support, stress, and depression: two longitudinal studies. J Res Person. 2008;42:854-871.

[36] Bono G, McCullough ME. Positive responses to benefit and harm: bringing forgiveness and gratitude into cognitive psychotherapy. J Cogn Psychother. 2006;20:2.

[37] Yalom I. Theory and Practice of Group Psychotherapy. 5th ed. New York: Basic Books; 2005.

[38] Craig P, Dieppe P, Mcintyre S, et al. Developing and evaluating complex interventions: the new Medical Research Council guidance. Br Med J. 2008;377:979-983.

[39] Abraham C, Michie S. A taxonomy of behavior change techniques used in interventions. Health Psychol. 2008;27:379.

[40] Michie S, Fixsen D, Grimshaw JM, et al. Specifying and reporting complex behaviour change interventions: the need for a scientific method. Implement Sci. 2009;4:40-41.
[41] Hobart J, Lamping D, Fitzpatrick R, et al. The multiple sclerosis impact scale (MSIS-29): a new patient-based outcome measure. Brain. 2001;124:962-973.

[42] Krupp LB, La Rocca NG, Muir-Nash J, et al. The fatigue severity scale. Application to patients with multiple sclerosis and systemic lupus erythematosus. Arch Neurol. 1989;46:1121-1123.

[43] Airlie J, Baker G, Smith J, et al. Measuring the impact of Multiple Sclerosis on psychosocial functioning: the development of a new self-efficacy scale. Clin Rehabil. 2001;15:259-265.

[44] Zigmond AS, Snaith RP. The hospital anxiety and depression scale. Acta Psychiatr Scand. 1983;67:361-370.

[45] Watson D, Clark LA, Tellegen A. Development and validation of brief measures of positive and negative affect: the PANAS Scales. J Person Soc Psychol. 1988;54:1063-1070.

[46] Nolte S, Elsworth G, Sinclair A, et al. The extent and breadth of benefits from participating in chronic disease selfmanagement courses: a national patient-reported outcomes survey. Patient Educ Counsel. 2007;65:351-360.

[47] Wallace L, Turner A, Kosmala-Anderson J, et al. Co-creating health: evaluation of first phase. London: The Health Foundation; 2012.

[48] Tickle-Degnen L. Nuts and bolts of conducting feasibility studies. Am J Occup Ther. 2013;67:171-176.

[49] Turner A, McHattie D, Martin F, et al. The HOPE group coaching and support programme for cancer survivors. UK Society of Behavioural Medicine 6th Annual Scientific Meeting, University of Leeds, 14-15 December; 2010.

[50] Hergenrather $K$, Rhodes S, Turner A, et al. Enhancing employment for persons with HIV/AIDS through self-management behavioral coaching. European Health Psychology Conference \& BPS Annual Health Psychology Conference, University of Bath, North East Somerset, UK; 2008.

[51] Puja J, Dave M, Christina M, et al. Evaluation of the HOPE programme: improving psychological well-being for parents of children with ASD/ADHD. 27th Conference of the European Health Psychology Society to be held in Bordeaux, France, from 16 to 20 July 2013.

[52] Druss BG, Zhao L, von Esenwein SA, et al. The health and recovery peer (HARP) program: a peer-led intervention to improve medical self-management for persons with serious mental illness. Schizophr Res. 2010;118:264-270.

[53] Seligman MEP. Positive health. Appl Psychol-Inter Rev. 2008;57:3-18.

[54] Veres A, Bain L, Tin D, et al. The neglected importance of hope in self-management programs - a call for action. Chronic Illness. 2014;10:77-80.

[55] Brooks HL, Rogers A, Sanders C, et al. Perceptions of recovery and prognosis from long-term conditions: the relevance of hope and imagined futures. Chronic Illness. 2015;11:3-20.

[56] Klausner E, Snyder CR, Cheavens J. A hope-based group treatment for depressed older adult outpatients. In: Willimason GM, Shaffer DR, Parmelee PA, editors. Physical illness and depression in older adults: a handbook of theory, research and practice. New York: Kluwer Academic/ Plenum Publishers; 2000.

[57] Cheavens J, Feldman D, Gum A, et al. Hope therapy in a community sample: a pilot investigation. Soc Indic Res. 2006;77:61-78. 
[58] Rosenberg JH, Shafor R. Fatigue in multiple sclerosis: a rational approach to evaluation and treatment. Curr Neurol Neurosci Rep. 2005;5:140-146.

[59] Schmitt MM, Goverover Y, DeLuca J, et al. Self-efficacy as a predictor of self-reported physical, cognitive, and social functioning in multiple sclerosis. Rehabil Psychol. 2014;59:27.

[60] McFarland L, Barlow J, Turner A. Understanding metaphor to facilitate emotional expression during a chronic disease self-management course. Patient Educ Counsel. 2009;77:255-259.
[61] Magaletta PR, Oliver JM. The hope construct, will, and ways: their relations with self-efficacy, optimism, and general wellbeing. J Clin Psychol. 1999;55:539-551.

[62] Barlow JH, Turner AP, Wright CC. A randomized controlled study of the arthritis self-management programme in the UK. Health Educ Res Theory Pract. 2000;15:665-680.

[63] Korostil M, Feinstein A. Anxiety disorders and their clinical correlates in multiple sclerosis patients. Mult Scler. 2007;13:67-72.

[64] Mayo E. The human problems of an industrial civilization. Volume 3. 2nd ed. New York: MacMillan; 1993. p. 53-73. 